\title{
Self-Concept and Self-Esteem
}

\author{
Rev. Sr. Amaka Obineli (Ph.D) \\ Department of Guidance and Counselling, \\ Faculty of Education \\ Nnamdi Azikiwe University, Awka.
}

http://doi.org/10.5281/zenodo.3831429

\begin{abstract}
An overview of the self-concept and its construction in children and adolescents is presented. The importance and educational implications of understanding the formation of the concept, and in particular self-image and self-esteem, are also considered. The benefits of self-esteem, enhancement on academic achievement, through parental and teacher influences are indicated.
\end{abstract}

\section{Introduction}

The individual's, sense of themselves will involve an awareness of mental and physical attributes, as well as social roles. Such self-awareness defines self-image and, as will be discussed below, begins to develop at an early age. Simultaneous with the development of the self-image is the ideal-self which is the individuals culmination of desirable characteristics. Standard and behaviour when realized, becomes a self-image and ideal self reflects the Individual's self-esteem. Self-esteem in turn may be displayed through the individual's confidence level overall contentment, and motivators fur new experiences and challenges. In the context of education therefore, the student's construct of the self may have important implications on the learning experience. In the following sections, discussion on the components of the self wilt be given. How children and adolescents construct an overall sense of themselves as individuals will then be addressed the importance (educational implications) of understanding of these processes for parents and teachers described.

\section{An Overview}

As mentioned above, the self-image is the individual's awareness of personal attributes. This is developed at an early age through the influences of the parents or guardians. For example, sex-role stereotyping by the parents, as well as feedback on or exaggeration of personal characteristics, may establish an early self-image and body image upon the child. The process continues in the school years through new experiences and influences (i.e. significant others, such Its peers and teachers. The self-image therefore can be deemed to develop through a "looking glass" (Cooley, 1999), which refers to image formation through feedback from others. Self

\section{Concept}


The sum of a person's perceived and desired mental and physical characteristics as well as the person's perceived worthiness from these, is often referred to as the se $1 \mathrm{f}$-concept. Thus, self-concept can be viewed as an "umbrella" term (Lawrence, 2003) which encompasses the selfimage, the ideal-self and the self-esteem of the individual, when an individual is asked to repetitively answer the question "who am I' the individual is likely to reveal the self-image, such as age and physical attributes, followed by aspects of the ideal-self and se 1 f-esteem, such as aspirations and perceived strengths and weakness. Thus, self-concept can be viewed as an overall interpretation of "who am I". (Lawrence 2003)

In early childhood (I.e. pre-school), the child's self-image is likely to focus on specific observable bebaviours and characteristics. That is, specific skills, possessions and is likely to be stated by the child to describe the self, and perceived personal attributes directly related to behaviours.. The child is unlikely to make reference to any relative evaluation of the self with respect to peer or society. This suggests that issues of an idealized self and thus self-worth are inconsequential to the child. Furthermore, uncritical self-evaluation or self-doubt may further result in the child exhibiting an inflated sense of abilities. Such characteristics of the child may be a reflection of the cognitive limitations at this stage of life (reaper- operational stage (Piaget (1952), and may in fact be beneficial in promoting, for example, an emotionally uninhibited approach to new experiences and challenges.

In middle childhood (i.e. adolescence), a greater sense of social awareness arises, possibly through the wide increase of significant others (e.g. Peers, teacher, and idols), as well as some internalization of the perceived values and norms of society. At his stage, statements of self-image will include emotionality labels, interpersonal references, as well as trait labels.

\section{Self-Esteem}

Issues of self-esteem are thus likely to arise in middle childhood. As indicated earlier, the selfesteem or self-worth of the child refers to a relative measure between the child's self-image and ideal (or desired) self ie. in the words of James (2000), self-esteem can be considered as the ratio of "our actualities to our supposed potentialities" A low self esteem therefore indicates a large discrepancy between the self-image and the ideal-self, and may be exhibited through-several operations by the child. (Lawrence, 2003)

* Avoidance; i.e. a student with low self-esteem and an introvert temperament may adopt the attitude that "with no attempt there can be no failure"

* Compensation; i.e. a student with low self-esteem ami extrovert temperament may

* exhibit boastful and 8JTogant behavior to cover an underlying inferiority complex (Jung, 1923)

* Low motivation; i.e. although the discrepancy between self-image and the ideal self may act as a motivator for personal development, if a student perceives a particular task as not relevant to their self-concept then as mention above little motivation for the task may be exhibited. 
* Resistance; i.e. the student will try to maintain the self-concept and change, even, if this

may be of benefit. Interest. Interestingly, students of low self-esteem are likely to offer the greatest resistance, so as to minimize risk.

The middle childhood individual will also begin to recognize the different components and domains in life, which influence their view and evaluation of themselves. This leads to the emphasis of the notion of situational and global self-esteem. The former describes self-esteem for a particular task or situation (e.g. Academic related), whereas the latter the overall, or sum-total, self-esteem. Such differentiation of self-esteem bas been used to explain why specific student inadequacy or incompetent is not necessarily reflected in the overall self worthiness of the individual. Furthermore, if the specific task is not of significance to the student's idealset,irrespective of its teacher-perceived value, then motivation for task itself will be low. For example, Lawrence (2003) describes cases of poor readers who actually have good linguistic and cognitive abilities in other task, but simply do not see reading as important to them.

\section{Constructing I and Me}

In adolescence, self-views are generally observed to become more stable (Purkey, 2005). However, some of the evaluations of the "Self may be rather hypothetical (e.g. unobservable or abstract). There is also greater emphasis by the individual on the psychological interior, such that students will often make references to, for example, depression, moodiness and sensitivity. It is perhaps the pressures and of academic pursuits, the cultural emphasis on success and assessment and peer pressure and competition, that particularly facilitate self-concept and self-esteem development at this stage of life (Bums, 2004). Likewise, adolescence may be particularly susceptible to the influences of media and advertisement, as they endeavor to establish as identity (self-concept) of themselves. Rote based abstractions also appear in adolescence, whereby the selfimage of the individual is perceived contextually, ie. a different self with different types of people (teachers, friends, parent). Such role-based self-image bas been explained by James (2000) through the distinction between "I", i.e. the self as knower, and the "meself, i.e. the self (or group) he or she encounters.

What may possibly drive the creations of me-self and why is it that very different and distinct me-seives arise in adolescence? It was mentioned earlier that in addition to the role of significant others. Which constitute the individual's the immediate environment influences may arise through a conceptualized notion of societal values and norms i.e. generalized others (Mead, 1999), Thus the generalized other involves inculcated notions (e.g. attitudes, expectations, of view) of some abstract social class or group, which an individual will adopt as one's own. Although the formation of a generalized other may have originally involved the specific attitudes of individuals, over time, the full complex of factors become inter-related and no longer reflect specific attitudes. It is perhaps through the influence o/'the generalized other that an individual may come to effectively interact within a group or society. Mead's theory therefore strongly emphasizes the social influence on the development of an individual s self-concept, but in this ease, there, is perhaps reinforcement of the self-image through a perceived looking glass, which arises 
from generalized constructs. In a group sense therefore, the me-self may be-viewed as a product of adoption (or perceived adoption) of a particular generalized other. However, perhaps a lack of adolescent, and thus possible inaccurate or incomplete cognitive interpretation, may lead to some volatility and inconsistency amongst an individual's multiple selves ("conflict of the mes" (James, 1890). With maturity, cognitive reasoning is believed to reduce the importance of social influences on the self-concept, and thus a greater consistency in character (Harter, 1993). However, it is unlikely that an individual could ever trulyftee of such influences (Reynolds, 2001).

\section{Educational Implications}

The social influences on the individual's sense of themselves would suggest possible interventionist programmes for the improvement in, for example, self-esteem. In an educational context the premise of such programmes bas been that there is a relationship between student achievement and self-esteem, and that improvement in self-esteem, will lead to improvement in achievement. Whilst research findings on this relationship are mixed, there is general agreement amongst researchers those students who are underachievement at school are also likely to have, low self-esteem (Burns, 2004). However, the direction of causality bas been of debate, i.e. is it low self-esteem, which causes underachievement, or is it underachievement, which causes low selfesteem? If the former case is true, then the parental and teacher roles (i.e. Significant others) in student achievement are apparent. Likewise, on a wider context, the role of an educational institute itself: through, for example, the creation of a generalized, other which defines its commitment and attitudes to education, must not be underestimated. In contrast, if low student self-esteem (academic or otherwise) is primarily an artifact of poor achievement, then perhaps assessment criteria, both in terms of appropriateness and methods of implementation, require reevaluation (see also the discussions of Gardner (1999) on assessment based on multiple intelligence, rather than the linguistic and logical-mathematical bias expressed in typical ' Western sphooling).

To date, the most convincing evidence for causality comes from research works, which attempt' to improve achievement by first improving self-esteem; see for example Brook, over et at. . (1965), Lawrence (1996), and the review of Andrews (1998). Such workers demonstrate that indeed an improvement in student self-esteem can lead to improvements in academic achievements and or interpersonal behavior. However, Bums (2004), indicates that whilst academic success raises or maintains self-esteem, it is self-esteem, which influences performance through, .for example, higher expectations, standards and motivation. This interdependency on self-esteem and achievement is also released through James' postulation that

Self esteem $\quad=\quad$ success/pretensions

Which may be also stated as

Self esteem $\quad=\quad$ achievement/expectation

Thus, high achievement may be realized through high expectations and high self-esteem, but as suggested by Burns, self-esteem itself may not be functionally independent of expectations. For example, students with a high specific self-esteem for a task, such as reading, may actually be underachieving in the task itself which would suggest low expectations or standards for the task 
and thus as inherent apathetic (low motivation) approach Under these circumstances, perhaps a clearer distinction is needed between self-esteem and motivation. In particular, if consideration. is given to the Yerkes-Dodson (2000) law of arousal and performance, then it is not too surprising to expect an optimum level of self-esteem for motivation. Thus, the optimal learning state is not necessarily one of low self-esteem, where issues of anxiety, resistance or avoidance may arise, or one of very high self-esteem, where issues not apathy and false confidence may arise, but one of an optimal level of self-esteem. Such an optimum of course, may be student and task specific, such that considerations need to be given to the student temperament (e.g. introvert-extravert nature) as well as prior experience in related task areas.

It is also important to note that research evidence that relationship between self-esteem and achievement does not necessarily hold true for general (global) self-esteem (or indeed an overall academic self-esteem). But for self-esteem for very specific subjects such as reading, mathematics and science; see, for example, the discussions and research reference of Huitt (1998). The implication here is that success in a particular subject or area does not need to involve a change in the student's self-concept or global self-esteem but perhaps, the student's expectation (or task-specific self-esteem) for future success. Interestingly, such a view has a some relation to the expectancy-value model for student learning (see, for example, Biggs and

Moore (1993). Nevertheless, for students of low overall self-esteem, who may for example be exhibiting behavioral, the benefits of task specific improvement of self-esteem may be considerable on the overall self-worth.

The above discussion on the research findings defining the inter-relationships between self-image and self-esteem lead to several implications for parents and teachers. For example, as significant others, and possible-proponents of a generalized other, efforts are needed to recognize specific problems of low self-esteem in the child/adolescent, and to act effectively to negate low self-esteem; see, also the discussions of Rosenberg (1965, 1979), Coppersmith (1967), and Andrews and Brown $(1988,1993)$ on the parental influences on self-esteem. The works of Carl Rogers (1961) may be particularly relevant here, whereby specific qualities of the teacher or parent are indicated to benefit student self-esteem, e.g. Non-judgmental acceptance of the child, genuineness, and empathy. These qualities are likely to lead to a trusting and communicative environment for leaning and development.

The social nature of self-concept suggests group activities, which may be particularly beneficial for enhancing self-esteem, as has been-demonstrated by Lawrence (1996). For such activities may lead to the student to experience positive feedback from peers, and thus a possible means of reassessing a poorly perceived' self-image (e.g. "circle-time" and "recalling the good times" activities). Certain activities could also provide students with opportunities to take risk, and thus challenge any existing avoidance or resistance traits (e.g." playing the hero or expert" activities). The specific nature of activities could, be adapted to suit the age group of concern. Finally, in order establish a positive ethos in the classroom and home (c . $£$ a favorable generalize other), the self-esteem of the teacher and parents are also of importance (Bums, 1915). Indeed, the qualities underlying good counselling skills are more likely to be identified with high self-esteem. One implication here is that the education community as a whole has a responsibility in providing 
teachers with a favourably working environment, and opportunities for personal growth, if indeed this is to be favourably reflected in student achievement.

\section{Conclusion}

An overview of how children and adolescents develop a sense of themselves as individuals has been presented. This considered aspects of self-image, self-esteem and selfconcept. Factors influencing self-esteem and the self-concept have been shown to comprise of social and cognitive issues, the former being deemed to be most significant. The social influences on the self-concept, as well as research findings which indicate a relationship between specific self-esteem and achievement, suggest that school-based intervention programmes may be beneficial in improving the academic performance of students of low self-esteem. Likewise, the role of parents in the individual's educational development must not be undervalued. 


\section{REFERENCES}

Andrews, A. (1998). Self-steem. The psychologist, July, 339.USAvol2: Ipage 14.

Andrews; Brown, G. W. (1988). Social support, onset of depression and personality: an exploratory analysis. Social psychology and psychiatric epidemiology, 23,99. London: Prentice Hatt.

Andrews, B; Brown, G.W. (1993). Self-esteem and vulnerability to depression: the concurrent validity of interview and questionnaire measures. Journal of abnormal psychology, 102,565 London: PrenticeHall.

Bachman J.G; O' Malley, P.M; Johnston. I. (1978), Youth in transition, vol; IV, ISR Michigan University.

Biggs, I. Moore. P.I. (1993). The process of leaning. London: Prentice Hall,

Brooker, W.B; Lepere J.M; Hamachek, D.E; Thomas, S; Erickson, E.L. (1965). Self concept of ability and school achievement 11,Co-operative research projects no 163 6.Michigan: Michigan State University.

Bums, R (1975). Attitudes to self and to three categories of others in a Students group. Education studies. 1,181. Michigan: Michigan State University.

Bums, R (2004). Self-concept development and education London: Holt, Rinehart And Winston.

Cooley, C. H (1999). Human nature and the social order. New York: Charles Scribner's Son. Coppersmiths; (1999). The antecedents of self-esteem, San Francisco: Freeman press.

Gardner, H. (1999). Intelligent reframed: multiple intelligence for the 21st century, New York: Basic Books.

Harter, S. (1993). Causes And consequences of low self-esteem in children and adolescents, in Baumeister, R.E; (ED.) Self-esteem: the puzzle of low se/f regard, New York: Plenum

Huitt, W. (1998). Educational psychology interactive: self-concept and self-esteem: http/Ctoron.VaIdosta.edu/whitt/co//regsys/se/f.

Ireson, J; Male D. (1999). Psychology of education. London: University of London press.

James, W. (2000). Principles of psychology. New York: Henry Holt.

Lawrence, D. (2003). Enhancing self-esteem in the classroom. London: 2- Ed; PCP Ltd.

Mead. G.H. (1999). Mind, self, and society. Chicago: University of Chicago press. Piaget, J. (1952). The origins of intelligence in children. New York.: International University Press,

Purkey, W.W. (2005). Self-concept and school achievement. New York: Prentice Hall. Reynolds, (2001), Private communication. New York: Prentice Hall.

Rogers, C.R. (1961). On becoming a person, Boston: Houghton Mifflin.

Rosenberg, M. (1965). Society and the adolescent self-image. Princeton: Princeton University press.

Rosenberg M. (1979). Conceiving the self. New York: Basic Books'

www.jgcsunizik.org

Rev. Sr. Amaka Obineli 
Yerkes, R.M. Dodson, J.D. (1908). The relationship of strength of stimulus to rapidity of habit formation: Comparative neurology and psychology, 18,459482. 